\title{
Immunological changes in patients with chronic heart failure
}

\author{
Bulat Kupenov, Olga Malgazdarova, Akmaral Moldazhanova, Zhanat Bekzhigitova
}

Cardiology Department, National Scientific Medical Center, Astana, Republic of Kazakhstan

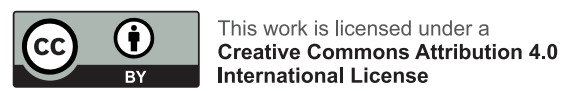

Received: 2018-03-15

Accepted: 2018-04-18

UDC: 616.1

\section{J Clin Med Kaz 2018;2(48):9-13}

Corresponding Author: Olga Malgazdarova, National Scientific Medical Center. Address: 42, Abylai Khan avenue, 010009, Astana, Republic of Kazakhstan. Tel.: +77052308581

E-mail: olga.bes84@mail.ru

\section{Abstract}

Chronic heart failure - symptom complex arising in the outcome of cardiovascular diseases of various etiologies. At the moment heart failure is widespread and has become a pandemic. This fact led to the need to clarify the known mechanisms of pathogenesis and the search for new ways of diagnostics therapy and ultimately to improve methods of monitoring the course of heart failure. The wide diagnostic possibilities of modern medicine did not give a clear understanding of the mechanisms of involvement of the immune system links in the pathogenesis of chronic heart failure. It remains an open question, concluded in the "cytokine theory" of the pathogenesis of chronic heart failure, about the cause-and-effect relationship of the immune response and heart failure.

Key words: chronic heart failure, left ventricular ejection fraction, cytokines, tumor necrosis factor, a-interleukins

СОЗЫЛМАЛЫ ЖУРЕК ЖЕТКІЛІКСІЗДІГІ БАР НАУҚАСТАРДАҒЫ ИММУНОЛОГИЯЛЫК ӨЗГЕРІСТЕР

Купенов Б.Г., Малгаздарова О.В., Молдажанова А.М., Бекжигитова Ж.Б.

Кардиология бөлімі, Ұлттық ғылыми медициналық орталық, Астана, Қазақстан Республикасы

\section{ТҰЖЫРЫМДАМА}

Созылмалы жүрек шамасыздығы - әртүрлі этиологиядағы жүрек-тамыр ауруларының салдарынан пайда болатын симптомдар кешені. Қазіргі кезде жүрек шамасыздығы кеңінен таралған және ол пандемия сипатын алған. Аталмыш факт патогенездің белгілі механизмдерін анықтау және диагностикасы мен емдеудің жаңа жолдарын іздестіру, және жүрек шамасыздығының ағымын бақылау тәсілдерін жетілдіру қажеттігіне соқтырған. Заманауи медицинаның кең диагностикалық мүмкіндіктері созылмалы жүрек жеткіліксіздігінің патогенезінде иммундық жүйенің байланыстарын тарту тетіктерін нақты түсініксіз. Созылмалы жүрек жетіспеушілігінің патогенезі, иммундық реакцияның және жүрек жеткіліксіздігінің себеп-салдарлық байланысы туралы «цитокиндік теориясында» ашық сұрақ болып қала береді.

Негізгі сөздер: созылмалы жүрек жеткіліксіздігі, сол жақ қарыншаның аластау фракциясы, цитокин, ісік некроз факторы, а-интерлейкиндер

\section{ИММУНОЛОГИЧЕСКИЕ ИЗМЕНЕНИЯ У ПАЦИЕНТОВ С ХРОНИЧЕСКОЙ СЕРДЕЧНОЙ НЕДОСТАТОЧНОСТЬЮ}

Купенов Б.Г., Малгаздарова О.В., Молдажанова А.М., Бекжигитова Ж.Б.

Отдел кардиологии, Национальный научный медицинский центр, Астана, Республика Казахстан

\section{РЕЗЮMЕ}

Хроническая сердечная недостаточность - симптомокомплекс, возникающий в исходе сердечно-сосудистых заболеваний различной этиологии. В настоящий момент сердечная недостаточность широко распространена и приобрела характер пандемии. Данный факт привел к необходимости уточнения известных механизмов патогенеза и поиску новых путей диагностики, терапии и в конечном итоге совершенствованию методов контроля течения сердечной недостаточности. Широкие диагностические возможности современной медицины не дали четкого понимания механизмов вовлечения звеньев иммунной системы в патогенез хронической сердечной недостаточности. Остается открытым вопрос, заключенный в «цитокиновой теории» патогенеза хронической сердечной недостаточности, о причинно-следственной связи иммунного ответа и сердечной недостаточности.

Ключевые слова: хроническая сердечная недостаточность, фракция выброса левого желудочка, цитокины, фактор некроза опухоли, $\alpha$-интерлейкины 
Согласно европейским рекомендациям по диагностике и лечению острой и хронической сердечной недостаточности 2016 года сердечная недостаточность $(\mathrm{CH})$ - клинический синдром, проявляющийся следующими характерными симптомами (одышка, пароксизмальная ночная одышка, ортопноэ, снижение переносимости физической нагрузки, увеличение времени для восстановления после физической нагрузки, отёки лодыжек, усталость), которые могут сопровождаться следующими признаками (повышение давления в ярёмных венах, гепато-югулярный рефлюкс, третий тон сердца, смещение верхушечного толчка влево), вызываемые структурными и/или функциональными изменениями сердца, приводящих к снижению работы сердца и/или повышению внутрисердечного давления в покое или при нагрузке.

Хроническая сердечная недостаточность (ХCH) развивается вследствие многих заболеваний сердечнососудистой системы как воспалительной, так и невоспалительной этиологии, в подавляющем большинстве случаев приводит к инвалидизации больных с утерей их социальной роли, существенному ухудшению качества жизни и, в конечном итоге, к значительному уменьшению продолжительности жизни [1-3].

По приблизительным подсчетам примерно 1-2\% взрослого населения в развитых странах имеют $\mathrm{CH}$, с увеличением риска развития свыше $10 \%$ среди населения в возрасте старше 70 лет [4]. При оценке гендерных различий частоты развития $\mathrm{CH}$ в возрасте свыше 55 лет риск развития составляет $33 \%$ и $28 \%$ для мужчин и женщин соответственно [5].

Долгое время предметом многочисленных исследований являлись механизмы систолической дисфункции миокарда, которую традиционно ассоциировали с тяжестью ХСН. Перед тем как симптоматика становится явной, пациент может наблюдаться со структурными или функциональными сердечными аномалиями (систолическая или диастолическая дисфункция левого желудочка (ЛЖ)), которые являются предшественниками $\mathrm{CH}$.

Начало терапии $\mathrm{CH}$ на стадии досимптомного течения позволяет улучшить прогноз заболевания и может значительно снизить смертность при наличии у пациента бессимптомной систолической дисфункции левого желудочка [6,7].

В последние десятилетия наблюдается рост количества пациентов, имеющих симптомы СН при отсутствии или наличии минимальных нарушений функции сердца, что заставляет исследовать роль диастолической дисфункции левого желудочка в течении и прогнозе СН. Согласно данным некоторых исследований наличие минимальной диастолической дисфункции может привести к увеличению риска смертности в 8 раз. [8]. Широкий спектр пациентов с $\mathrm{CH}$ варьирует от тех, у кого нормальная фракция выброса левого желудочка (ФВЛЖ) (обычно считается $\geq 50 \%$; $\mathrm{CH}$ сФВ) до пациентов со сниженной ФВЛЖ (меньше 40\%, СНнФВ). Пациенты с ФВ в диапазоне 40-49\% находятся в так называемой «серой зоне», которая сейчас обозначается как СН-срФВ.

Анализ популяционных исследований указывает на то, что распространенность ХСН с сФВ в мире составляет от 40 до 70\% (в среднем 54\%). Среди людей старше 65 лет с впервые выявленной одышкой при физической нагрузке один из шести будет иметь нераспознанную СН (в основном
СН-сФВ) [9,10]. Специалистами прогнозируется, что проблема терапии пациентов с ХСН станет одной из самых главных проблем кардиологии в ближайшие десятилетия [11].

Несмотря на вышеизложенное продолжаются дискуссии о необходимости терапии бессимптомной или малосимптомной дисфункции ЛЖ с сохраненной ФВ ЛЖ. Важность решения данного вопроса подчеркивает тот факт, что число таких пациентов как минимум в пять раз превосходит число зарегистрированных случаев СН $[12,13]$.

Вместе с тем остаются не до конца понятными процессы формирования патофизиологических механизмов $\mathrm{XCH}$. Одним из путей формирования патологического процесса признана роль активации системы цитокинов [14, 15].

До сих пор не ясно, какую роль играет системная воспалительная реакция в нарушениях гемоциркуляции, а также в формировании эндокардиальной и миокардиальной дисфункции. К тому же выявлена прямая взаимосвязь в увеличении экспрессии уровня цитокинов при наличии дисфункции ЛЖ [16]. Значение системного воспаления в патогенезе ХCH активно исследуется в настоящее время. Особое значение уделяется изучению процессов индукции иммунных реакций, а также их механизмов, приводящих к ремоделированию сердца.

Причиной увеличения содержания провоспалительных цитокинов при ХCH Adamopoulos и соавторы связывают с неспецифической активацией макрофагов и моноцитов в плазме крови и межтканевой жидкости, происходящей при тяжелых расстройствах микроциркуляции, тканевой гипоксии и избытком свободных радикалов, возникающим вслед за повреждением миокарда и падением сердечного выброса $[17,18]$.

Существует иная точка зрения о причинах иммунной активации при наличии тяжелой дисфункции ЛЖ, которая заключается во взаимодействии с иммуннокомпетентными клетками эндотоксинов микроорганизмов в кишечнике, контаминация которыми возрастает при наличии СН [19].

S.R. Kapadia и соавторы выдвинули гипотезу миокардиальной продукции провоспалительных цитокинов, поскольку кардиомиоциты способны продуцировать цитокины при повышении уровня конечного диастолического давления в левом желудочке.

Первопричиной патологической активации иммунного ответаможетпослужить гипоксия миокарда и развивающаяся вследствие этого гипоксия периферических тканей. Данное утверждение подтверждается прямопропорциональной зависимостью между классом тяжести ХСН и уровнем провоспалительных цитокинов [20].

Несмотря на наличие различных теорий в запуске патологического процесса $\mathrm{CH}$, большинство исследователей относят активацию провоспалительных цитокинов к числу первопричин развития и прогресса ХСН.

Убедительныедоказательства одной изпервостепенных ролей провоспалительных цитокинов в патогенезе ХCH получены в работе B.Bozkurt и соавторов. В эксперименте на крысах длительная инфузия ФНО- $\alpha$ привела к дилатации желудочков сердца крыс со снижением сократительной способности сердца [21].

Иммунная система организма активируется не только при инфекционных агрессиях, но реагирует также на факторы, которые являются этиологическим факторами 
развития ХCH (ишемия миокарда, гемодинамическая нагрузка). Главные компоненты иммунной системы, задействованные в развитии ХCH: провоспалительные цитокины, молекулы адгезии, аутоантитела, эндотелины, оксид азота.

К группе цитокинов относится около 300 молекул, которые представляют собой класс растворимых пептидных медиаторов иммунной системы, осуществляющих еe развитие, функционирование и взаимодействие с другими системами организма человека. Согласно осуществляемой ими биологической роли, все цитокины можно разделить на три группы: провоспалительные, противовоспалительные и кардиопротективные.

Цитокины обладают уникальными свойствами: способны действовать на различные клетки-мишени, регулируя их функцию; различные цитокины способны оказывать сходный биологический эффект [23].

Цитокины оказывают по большей части паракринный, либо аутокринный эффекты; лишь некоторые оказывают системное действие (фактор некроза опухоли- $\alpha$, интерлейкин-1) [24].

К цитокинам относятся следующие основные группы агентов: интерлейкины (включающие в себя лимфокины и монокины), фактор некроза опухоли, хемокины. Выделены два основных класса провоспалительных цитокинов, принимающих участие в патогенезе СН: вазоконстрикторные цитокины (большой эндотелин, эндотелин-1) [25] и вазодепрессорные провоспалительные цитокины (ФНО- $\alpha$, ИЛ-1, ИЛ-6 и ИЛ-8).

Благодаря ФНО-опосредованной индукции генов происходит избыточная продукция широкого спектра провоспалительных агентов (факторов роста, цитокинов, медиаторов, белков острой фазы воспаления, пирогенов), имеющих ключевую роль в патогенезе СН. Впервые зависимость уровня ФНО- $\alpha$ в сыворотке крови у пациентов с СН и тяжести функционального класса СН была выявлена B.Levine и соавторами в 1990 г [26].

Под воздействием ФНО- $\alpha$ увеличивается количество цитокин-индуцированной NO, которая в свою очередь подавляет выработку эндотелиального NO, тем самым ухудшая функцию эндотелия. NO оказывает свои эффекты также путем активизации процессов фиброза, что, в конечном итоге, приводит к ремоделированию сердца. [16]. Кроме того, образующийся в процессе взаимодействия NO и супероксидных анионов, пероксинитрат, является высоко реактивным оксидантом, также способным оказывать цитотоксическое действие, окислять липиды, повреждать клеточные мембраны, существенно снижать сократительную способность миокарда [27].

ФНО-а оказывает свои эффекты путем активации апоптоза, который утрачивает свое адаптивное значение и приводит снижению количества жизнеспособных кардиомиоцитов, что в дальнейшем приводит к прогрессирующему снижению сократительной функции миокарда. Процесс активации апоптоза происходит путем связывания ФНО-а с так называемыми рецепторами смерти на поверхности кардиомиоцитов. Активация рецепторов смерти и оксидативный стресс кардиомиоцитов, усиливающийся под влиянием ФНО-а, запускают каспазный каскад, что в конечном итоге запускает генетически запрограммированную гибель клеток.

ФНО- $\alpha$ способен также оказывать непосредственное токсическое действие на кардиомиоциты.

Роль других провоспалительных цитокинов в патогенезе развития ХСН также доказана в результате многочисленных исследований [16,27].

ИЛ-1 принимает участие в прогрессировании фиброза миокарда и ухудшении течения $\mathrm{CH}$ [27], играет важную роль в атеросклерозе, способствуя формированию атеросклеротических поражений, усилению сосудистого воспаления и триггерному спуску дестабилизации бляшки [14]. ИЛ-1 участвует в развитии неблагоприятного ремоделирования за счет повышения экспрессии матричных металлопротеиназ. ИЛ-1 обладает способностью нарушать функцию сердечной мышцы путем подавления сократительной способности миокарда, способствуя прогрессированию гипертрофии миокарда и вызывая апоптоз кардиомиоцитов [28].

ИЛ-6, как и вышеописанные провоспалительные цитокины, относится к цитокинам системного действия. Проспективные исследования свидетельствуют, что высокий уровень ИЛ-6 в плазме крови является достоверным и независимым предиктором развития ИМ у здоровых людей, a также общей смертности у пожилых. Также выявлено более значимое повышение уровня ИЛ-6 у пациентов с инфарктом миокарда в острую стадию, особенно при наличии симптомов ХСН вкупе со сниженной ФВ ЛЖ, по сравнению с уровнем данного цитокина у пациентов со стабильным течением ишемической болезни сердца.

Чтобы оценить возможную взаимосвязь между уровнем провоспалительных цитокинов и тяжестью течения ХСН, произведен анализ этих данных у больных повторно госпитализированных или умерших в связи с декомпенсацией ХСН. Было выявлено, что неблагоприятное течение ХCH с рецидивами и повторной госпитализацией, а также со смертельными исходами на фоне декомпенсации сердечной недостаточности ассоциируется с существенным возрастанием уровня провоспалительных цитокинов, несмотря на массивную комбинированную патогенетическую терапию [29].

Подтвержденные данные касательно участия ФНО- $\alpha$ в развитии ХСН привели к разработке двух лекарственных препаратов, механизм действия которых заключен в связывании и нейтрализации цитокина: этанерсепт-белок, представляющий собой внеклеточный домен человеческого рецептора Р-75 к ФНО- $\alpha$ и инфликсимаб, относящийся к группе моноклональных антител, связывающийся как с растворимым, так и с трансмембранным ФНО- $\alpha$ с высокой аффиннностью [30].

Однако, положительный эффект данных лекарственных препаратов на течение и прогноз ХCH по результатам крупных исследований с этанерсептом (RECOVER и RENAISSANCE) и с инфликсимабом (ATTACH) не доказан. Напротив, исследования были прекращены досрочно ввиду роста частоты госпитализаций и смертности у пациентов, получавших инфликсимаб.

Имеются данные о том, что применение препаратов, обладающих ингибирующим влиянием на ФНО- $\alpha$ у больных $\mathrm{XCH,} \mathrm{улучшает} \mathrm{сократительную} \mathrm{функцию} \mathrm{ЛЖ} \mathrm{и} \mathrm{прогноз}$ больных [31]. Одним из них является пентоксифиллин, производное ксантина, который предотвращает транскрипцию ФНО- $\alpha$, блокируя внутриклеточную аккумуляцию и РНК этого цитокина [32]. Благоприятное влияние пентоксифиллина на прогноз и течение ХCH 
доказано в исследованиях, проведенных K.Silva и соавт. Добавление пентоксифиллина к стандартной терапии привело к улучшению клинического состояния больных и увеличению ФВ ЛЖ, что сопровождалось уменьшением уровня маркеров воспаления (мозговой натрийуретический пептид, С-реактивный белок, ФНО- $\alpha$ ) и апоптоза [33].

Участие звеньев иммунной системы в патогенезе ХСН является сравнительно новым учением в современной кардиологии, что требует более детального изучения с проведением крупных сравнительных проспективных исследований. Активация системы цитокинов у больных с $\mathrm{XCH}$ является маркером прогрессирования заболевания и определяет тяжесть течения $\mathrm{CH}$, патогенетические эффекты цитокинов реализуются различными путями, что требует особой фармакотерапевтической тактики у этих пациентов. Выделение отдельных групп СН с небольшим снижением ФВ ЛЖ и с сохраненной ФВ ЛЖ также требует изучение подробных характеристик, патофизиологии пациентов этой группы, с определением терапевтической тактики, этому может способствовать дальнейшее изучение иммунологических изменений у пациентов с ХCH.

Disclosures: There is no conflict of interest for all authors.

\section{Список литературы}

1. Belenkov Ju.N., Ageev F.T., et al. Epidemiologija i prognoz hronicheskoj serdechnoj nedostatochnosti (Epidemiology and Prognosis of Chronic Heart Failure) [in Russian]. Russkij medicinskij zhurnal. 1999; 2:51-56.

2. Belenkov Ju.N., Mareev V.Ju., Ageev F.T. Medikamentoznye puti uluchshenija prognoza u bol'nyh s serdechno jnedostatochnost'ju (Medications for improving the prognosis in patients with heart failure) [in Russian]. M.; «Insajt». 1997:77.

3. Cobn J.N. The management of chronic heart failure. N Engl J Med. 1996; 335: 490-8.

4. Mosterd A., Hoes A.W. Clinical epidemiology of heart failure. Heart. 2007; 93:1137-1146.

5. Bleumink G.S, Knetsch A.M., Sturkenboom MC JM, Straus SM JM, Hofman A, Deckers J, Witteman JCM, Stricker BHC. Quantifying the heart failure epidemic: prevalence, incidence rate, lifetime risk and prognosis of heart failure The Rotterdam Study. EurHeartJ England. 2004;25:1614-1619.

6. Wang TJ. Natural history of asymptomatic left ventricular systolic dysfunction in the community. Circulation. 2003; 108:977982.

7. The SOLVD Investigators Effect of enalapril on mortality and the development of heart failure in asymptomatic patients with reduced left ventricular ejection fractions. N Engl J Med. 1992; 327:685-691.

8. Redfeid M. et al. Burden of systolic and diastolic ventricular dysfunction in the community appreciating the scope of the heart failure epidemic. JAMA. 2003; 289, 194-202.

9. VanRietEES, Hoes AW, Limburg A, Landman MAJ, Van der Hoeven H, Rutten FH. Prevalence of unrecognized heart failure in older persons with shortness of breath on exertion. Eur J Heart Fail. 2014; 16:772-777.

10. Filippatos G, Parissis JT. Heart failure diagnosis and prognosis in the elderly: the proof of the pudding is in the eating. Eur J Heart Fail. 2011; 1:467-471.

11. Cleland J.G.F, Mac Cown J. Heart failure due ischemic heart disease: epidemiology, pathophysiology and progression. $J$. Cardiovasc. Pharmacol. 1999; 33(3): 17-29.

12. Klimov A.N., Denisenko A.D., Popov A.V. et al. Lipoprotein antibody immune complexes, their catabolism and role in foam cell formation.Atherosclerosis. 1985; 58: 1-15.

13. Kendall M.J., Zynch K.P., ITjalmerson A., Kjekshus J. P-blockers and sudden cardiac death. Ann. Intern. Med. 1995; 123: 358367.

14. M. Hedayat (et al). Proinflamattory cytokines in heart failure: double-edged swords. Heart Fail Rev.2010; 6: $543-562$.

15. V.V.Kaljuzhini dr. Patogenez hronicheskoj serdechnoj nedostatochnosti: izmenenie dominirujushhej paradigm (Patogenesis of chronic heart failure: a change in the dominant paradigm) [in Russian]. Bjul. Sib.Med. 2007;4: 71-79.

16. Vasjuk Ju. A. Citokinovaja model' patogeneza hronicheskoj serdechnoj nedostatochnosti i vozmozhnosti novogo terapevticheskogo podhoda $\mathrm{v}$ lechenii dekompensirovannyh bol'nyh (Cytokine model of the pathogenesis of chronic heart failure and the possibility of a new therapeutic approach in the treatment of decompensated patients) [in Russian]. Farmakoterapija v kardiologii. 2006; 4:63-70

17. Adams V., Jiang H., Yu J. et al. Apoptosis in skeletal myocytes of patients with chronic heart failure is assotiated with exercise intolerance. J Am CollCardiol. 1999, 33: 959-65.

18. Keith M., GeranmayeganA., Sole M. et al. Increased oxidative stress in patients with congestive heart failure.JAmCollCardiol.1998; 31: 1352-6.

19. Anker S.D., Egerer k., Vork H.D. et al. Elevated soluble CD 14 receptore and altereted cytokines in chronic heart failure. AmJCardiol.1997; 79: 1426-30.

20. Hasper D., Hummel L., Kleber F.X. et al. Systemic inflammation in patients with heart failure. Eur Heart J. 1998; 19: 761-5.

21. Bozkurt B., Kribbs S.B., Clubb F.J. et al. Pathophysiologically relevant concentration of tumor necrosis factor- $\alpha$ promote progressive left ventricular dysfunction and remodeling in rats. Circulation. 1998; 97: 1382-92.

22. Simbircev S.V. Citokiny: klassifikacija i biologicheskie funkcii. Citokinyivospalenie. (Cytokines: classification and biological functions. Cytokines and inflammation.) [in Russian]. 2004;3, 2: 16-22.

23. N.A. Smart et al. Effects of exercise training on IL-6, TNF- $\alpha$ and functional capacity in heart failure. Cardiol.Res.Pract. 2011; 2011: 6 .

24. Belenkov Ju.N., MareevV.Ju. Principy racional'nogo lechenija serdechnoj nedostatochnosti (Principles of rational treatment of heart failure) [in Russian]. M.: Media Medika, 2000: 10-16. 
25. McCormack JG, Barr RL, WolfAA., et al. Ranolazine stimulates glucose oxidation in normoxic, ischaemic and reperfusedischaemic hearts. Circulation. 1996; 93: 135-45.

26. B. Levine, J.Kalman, L.Mayer Elevated circulating levels of tumor necrosis factor in severe chronic failure. New Engl.J.Med. $1990 ; 32: 236-241$.

27. A.Abbate, F.N. Salloum, B.W.VanTassel.Alternations in the intrleukin-1/ intrleukin-1 Receptor Antagonist Balance Modulate Cardiac Remodeling following Myocardial Infarction in the Mouse. PLos One. 2011; 11: 2792-3.

28. R.Deardorrf, F.G. SpinaleCytokines and Matrix metalloproteinases as potential biomarkers in chronic heart failure. Biomark Med.2009;3, 5: 513-523.

29. O.P. Dudarenko, E.L. Shkol'nik, K.G. Kulikov, M.K. Serova, Ju.A. Vasjuk. Ingibitor sinteza faktora nekroza opuholi- $\alpha$ pentoksifillin v kompleksnoj terapii hronicheskoj serdechnoj nedostatochnosti (The inhibitor of the synthesis of tumor necrosis factor- $\alpha$ pentoxifylline in the complex therapy of chronic cardiac insufficiency) [in Russian]. Racional'najafarmakoterapija $v$ kardiologii.2008; 2:12.

30. Krum H. Tumor Necrosis Factor Alpha Blockade as a Therapeutic Strategy in Heart Failure (RENEVAL and ATTACH): Unsuccessful To Be Specific.Journal of Cardiac Failure. 2002; 6:8.

31. Bergman M.R., Holycross B.J. Pharmacological modulation of myocardial tumor necrosis factor a production phosphodiesterase inhibitore. Pharmacolexpther. 1996; 44: 247-54.

32. Torre-Amione G., Stetson S.S., Farmer J.A. Clinical implications of tumor necrosis factor a antagonist in patients with congestive heart failure. Ann Rheum Dis. 1999; 58 (Suppl 1): 1103-6.

33. Silwa K., Woodiwiss A., KoneV.N.,Candy G., Badenhorst D., Norton G., Zambakides C., Peters F., Essop R. Therapy of ischemic cardiomyopathy with the immunomodulating agent pentoxifelline: results of a randomized study. Circulation. 2004 ; 109 (6): $750-5$.

How to cite this article: Bulat Kupenov, Olga Malgazdarova, Akmaral Moldazhanova, Zhanat Bekzhigitova. Immunological changes in patients with chronic heart failure [in Russian]. J Clin Med Kaz. 2018; 2(48):9-13 